\title{
Response of Astrocytes to Blood Exposure due to Shunt Insertion in vitro
}

\author{
Mira Zaranek ${ }^{1}$, Rooshan Arshad ${ }^{1}$, Kevin Zheng ${ }^{1}$, and Carolyn Harris ${ }^{1}$ \\ ${ }^{1}$ Wayne State University
}

May 19, 2021

\begin{abstract}
The breakdown of the ventricular zone (VZ) with the presence of blood in cerebrospinal fluid (CSF) has been shown to increase shunt catheter obstruction in the treatment of hydrocephalus, but the mechanisms by which this occurs are generally unknown. Using a custom-built incubation chamber, we immunofluorescently assayed cell attachment and morphology on shunt catheters with and without blood after 14 days. Samples exposed to blood showed significantly increased cell attachment (average total cell count $392.0 \pm 317.1$ versus control of $94.7 \pm 44.5, \mathrm{P}<0.0001)$. Analysis of the glial fibrillary acidic protein (GFAP) expression showed similar trends $(854.4 \pm 450.7$ versus control of $174.3 \pm 116.5, \mathrm{P}<0.0001)$. An in vitro model was developed to represent the exposure of astrocytes to blood following an increase in BBB permeability. Exposure of astrocytes to blood increases the number of cells and their spread on the shunt.
\end{abstract}

Title: Response of Astrocytes to Blood Exposure due to Shunt Insertion in vitro

Authors:

Mira Zaranek, Wayne State University Dept. of Chemical Engineering and Materials Science, 6135 Woodward Avenue, Detroit, MI 48202

Rooshan Arshad, MESc, Wayne State University Dept. of Chemical Engineering and Materials Science, 6135 Woodward Avenue, Detroit, MI 48202

Kevin Zheng, Wayne State University Dept. of Chemical Engineering and Materials Science, 6135 Woodward Avenue, Detroit, MI 48202

Carolyn A Harris, PhD, Wayne State University Dept. of Chemical Engineering and Materials Science, 6135 Woodward Avenue, Detroit, MI 48202

\section{Abstract}

The breakdown of the ventricular zone (VZ) with the presence of blood in cerebrospinal fluid (CSF) has been shown to increase shunt catheter obstruction in the treatment of hydrocephalus, but the mechanisms by which this occurs are generally unknown. Using a custom-built incubation chamber, we immunofluorescently assayed cell attachment and morphology on shunt catheters with and without blood after 14 days. Samples exposed to blood showed significantly increased cell attachment (average total cell count 392.0 \pm 317.1 versus control of $94.7 \pm 44.5, P<0.0001$ ). Analysis of the glial fibrillary acidic protein (GFAP) expression showed similar trends $(854.4 \pm 450.7$ versus control of $174.3 \pm 116.5, P<0.0001)$. An in vitromodel was developed to represent the exposure of astrocytes to blood following an increase in BBB permeability. Exposure of astrocytes to blood increases the number of cells and their spread on the shunt.

\section{Keywords}


Ventricular Catheter, Posthemorrhagic Hydrocephalus, Blood Brain Barrier, Hemorrhage

\section{Introduction}

The condition hydrocephalus can be distinguished as the dilation of the cerebral ventricles due to an excessive accumulation of cerebrospinal fluid (CSF) ${ }^{(1)-(4)}$. This fluid buildup can be caused by an imbalance between the production and absorption of the CSF within the brain with the root variable etiology, including precursors such as hemorrhage, congenital malformations, and tumors ${ }^{(1),(2),(5)}$. Treatment typically involves the insertion of a shunt system, including a shunt catheter into the brain's ventricular space to drain excess CSF (6). Shunt failure is one of the highest among all neurological devices with 40-50\% requiring revision within the first two years and $80 \%$ within 10 years ${ }^{(7),(8)}$. Obstruction of the ventricular catheter accounts for $70 \%$ of shunt failures, which makes it the most prevalent failure modality compared to infection, over-drainage, and loculated ventricles ${ }^{(6)}$. The dominant cell types involved in the blocking of these holes are astrocytes and cells of the monocyte-macrophage lineage, suspected to be due to inflammatory stimuli ${ }^{(6),(9),(10)}$.

Posthemorrhagic hydrocephalus (PHH), one of the most common forms of hydrocephalus, is a result of an intraventricular hemorrhage (IVH). In premature infants, IVH is generally a consequence of a germinal matrix hemorrhage (GMH); in adults, IVH can result from an intracerebral hemorrhage (ICH) (11)-(13). The development of PHH in adults begins with an ICH that advances into an IVH in $42-52 \%$ of adult patients ${ }^{(11)}$. For neonates born prematurely, $20 \%$ develop an IVH or GMH, while $50 \%$ of those individuals develop $\mathrm{PHH}^{(14)}$. These hemorrhages introduce blood into the CSF, resulting in the disruption of cells of the ventricular zone (VZ) that leads to increased dilation and permeability of the ventricle $e^{(2),(14)}$.

In addition to etiology, blood brain barrier (BBB) breakdown from shunt insertion can play a major role in the CSF blood content ${ }^{(10),(15),(16)}$. The BBB, like the ventricular zone, is composed of a layer of ependymal cells held together by tight junctions regulating the movement of molecules, ions, and cells between the blood and the interstitial fluid of the brain ${ }^{(16)}$. Initial insertion of the ventricular catheter is concurrent with the trauma resulting in the disruption of cells, tissue, and blood vessels. This disruption during shunting can cause hemorrhages and edema in the ventricular space ${ }^{(17)}$. Edema reaches a maximum at day one postsurgery while healing of the BBB insult can take two to three weeks resulting in further exposure of the VZ to blood products ${ }^{(15),(17),(18)}$. Disruption of the VZ, following blood exposure, is a result of an overall loss of ependymal cells allowing for increased CSF accumulation and prolonged inflammation ${ }^{(11)}$. Ependymal cell loss can be attributed to cell junction dislocation and neural stem cell (NSC) differentiation impairment creating denuded areas for astrocyte exposure to the blood products ${ }^{(13),(14)}$.

An inflammatory response occurs within the ventricles following the infiltration of blood, which stimulates the activation of astrocytes and microglia ${ }^{(10),(19)}$. This astrocyte and microglia activation is maintained for up to 28 days post shunt insertion ${ }^{(20)}$. Glial activation is a result of various cytokines and growth factors produced by the activated microglia and leads to the rapid proliferation of astrocytes ${ }^{(20)-(22)}$. In response to this activation, an astrocyte layer is created to cover the denuded areas, from loss of ependymal cells, which was shown to increase cellular migration and attachment to the shunt surface ${ }^{(19),(23)}$. Blood within the CSF has been shown, in vivo, to cause an increase in shunt obstruction causing failure making up $34.8 \%$ of shunt revisions ${ }^{(24)}$. It has been theorized that the loss of VZ integrity allows for a higher infiltration of astrocytes into the ventricular zone by astrogliosis ${ }^{(14)}$.

The current study aims to investigate the impact of whole blood exposure on mouse astrocyte cells and its direct influence on ventricular shunt catheter obstruction. In this way, we examine the role blood plays on the foreign body response to chronic indwelling shunt catheters. Other studies have shown that the disruption of ependymal layer in the VZ allows for the activation of astrocytes resulting in the infiltration into the ventricular space ${ }^{(25)}$. In this study anin vitro model has been developed to mimic the introduction of blood to the CSF by breaking of the BBB following catheter insertion and the response of astrocytes to this stimulus is evaluated. This 3D model can be applied in various tests to allow for a catheter to be exposed to various stimuli in static culture. We hypothesize that the activation of astrocytes will occur when exposed to blood over a two-week period, representing the healing time of the permeable BBB, and result in an increase 
of cellular attachment to the surface of the catheter.

\section{Methods and Materials}

\section{Shunt Creation}

Medical grade barium-impregnated silicone catheter tubing with an outer diameter of $2.8 \mathrm{~mm}$ and inner diameter of $1.5 \mathrm{~mm}$ (Medtronic, Minneapolis, MN) were cut into 2-centimeter segments. To mimic the conical shape of hole in industrial made catheters, eight holes were punched using a $0.5 \mathrm{~mm}$ diameter leather punch $1.25 \mathrm{~mm}$ apart. Dimension used followed those seen in Medtronic catheters. The catheter was rotated 90 degrees, two times, repeating the punching process to create a total of three rows of eight holes. Excess catheter material left over after punching the holes was removed using tweezers. The final dimensions of the catheter holes were $0.5 \mathrm{~mm}$ outer diameter with $1 \mathrm{~mm}$ edge to edge separation, confirmed with confocal microscopy (Figure 5). The outer diameter was measured to ensure this method resulted in accurate dimensions after manually punching the samples. Sterilization of these samples began with a onehour incubation in $10 \%$ bleach. Following this, a series of washes included a 30-minute incubation in ethanol followed by two 10-minute washes with double distilled cell culture water (Growcells, Irvine, CA). Phenol red (v/v 1\%) (Sigma, St. Louis, MO) was added into the last wash to observe if a color change occurred, ensuring all ethanol was removed.

\section{Novel Blood Contact Model System, Glass Coverslip Coating, and Sterilization}

Creation of the resin 3D-printed chambers utilized Autodesk's Fusion 360 and Photon Workshop V2.1.24 software to design and slice the model for printing. Set up of the ANYCUBIC Photon S SLA 3D resin printer required the leveling of the build plate and vigorous shaking of the Sculpt High Temperature Resin from Siraya Tech for five minutes. Approximately $150 \mathrm{~mL}$ of resin was poured into the resin vat before beginning the print.

Once printing was completed, the chambers were left to soak in ethanol overnight. The next day, the chambers were hand dried and placed into a dehydrator for 30 minutes to remove excess ethanol. During the last five minutes of drying the chambers, a glass container was filled with enough water to fully submerge the print. The water was heated until it was warm to the touch. Once the drying process concluded, the chambers were exposed to UV light on all sides in two 15-minute increments for a total of 30 minutes, completely curing the prints.

After curing, the prints were placed back into the dehydrator for 30 minutes to remove the excess volatile organic compounds (VOCs) within the resin. A glass coverslip (Thomas Scientific, Swedesboro, NJ) was added into each well as the substrate to seed the cells onto. The glass coverslip was bound to the base of the well using Loctite Clear Silicone Waterproof Sealant and Loctite Professional Super Glue placed with an 18-gauge needle. Finally, the chamber was dehydrated for a final 15 minutes to completely remove any excess VOCs left after the addition of glue.

Sterilization of the chambers was done by soaking them in $70 \%$ (w/v) ethanol for 30 minutes followed by two 10-minute washes with double distilled water (Growcells, Irvine, CA). Before seeding the cells on the glass coverslip, the chambers were coated with $500 \mu \mathrm{L}$ of a $50 \mu \mathrm{g} / \mathrm{mL}$ poly-D-lysine solution overnight with phenol red (v/v 1\%). The next morning, glass coverslips were rinsed with $500 \mu \mathrm{L}$ of double distilled water containing phenol red (v/v 1\%) (Sigma, St. Louis, MO) and left to dry for two hours before seeding.

\section{$\mathrm{pH}$ Tests}

During the sterilization process, washes with double distilled water with $1 \%(\mathrm{v} / \mathrm{v})$ phenol red was used to observe color changes to ensure the ethanol was effectively removed. Insignificant color change showed that the majority of the ethanol was removed. Following sterilization, the glass coverslips were coated with poly-D-lysine with phenol red added overnight, and the next morning no color change was observed. The addition of $1.86 \mathrm{~g}$ of sodium bicarbonate was supplemented into the media to balance the $\mathrm{pH}$ within the system. 


\section{Blood Extraction and Storage}

Blood storage buffer was created using the standard concentrations for the citrate-phosphate-dextrose with the addition of adenine (CPDA-1) buffer. On top of the CPDA-1 buffer, additive solution three (AS-3) was combined with the blood to provide extra nutrients ${ }^{(26)}$. Briefly, a mixture of sodium citrate tribasic dehydrate, citric acid, dextrose, adenine, sodium phosphate monobasic, and sodium chloride were dissolved in double distilled water to create the buffer solution (Sigma, St. Louis, MO). Due to the small volume of buffer required, the reagents were massed and dissolved in $1000 \mu \mathrm{L}$ of double distilled water. The necessary volume of the reagent was then combined and brought to $5 \mathrm{~mL}$ with excess double distilled water.

All animal protocols were approved by the Wayne State University Institution of Animal Care and Use Committee (IACUC). Extraction of blood from a C57BL/6 male mice was performed using a full body massage, similar to a retro-orbital massage, technique following euthanasia via carbon dioxide and consequent decapitation. Microcentrifuge tubes, filled with $122.8 \mu \mathrm{L}$ of citrate buffer, were used to collect the blood. Each tube was filled with $877.2 \mu \mathrm{L}$ of blood to obtain a $1 \mathrm{~mL}$ final volume. After extraction, the blood was immediately placed on ice until added to the cell culture media. For long term storage, the tubes of blood were kept at $4^{\circ} \mathrm{C}$.

\section{Cell Culturing and Catheter Insertion}

Mouse primary astrocytes, Type III clone from the brain and cerebellum, were used for these experiments (ATCC C8-D30). The recommended cell culture media (ATCC) was a mixture of Dulbecco's Modified Eagle's Medium (DMEM) with supplemental $50 \mathrm{~mL}$ of fetal bovine serum. The addition of $5 \mathrm{~mL}$ of penicillinstreptomycin solution was also added into the media. Stabilization of the $\mathrm{pH}$ within the culture was accomplished by adding 1.86 grams of sodium bicarbonate was added into the media. Cells were allowed to grow in vented T75 Tissue Culture Treated Flasks (Falcon) for two weeks with media changes every three days. Cell removal was done using $2 \mathrm{~mL}$ of Trypsin-EDTA (v/v 0.25\%) with phenol red (Gibco, Waltham, MA) incubated at $37^{\circ} \mathrm{C}$ with a $\mathrm{CO}_{2}$ level of $5 \%$ for five minutes. Following the incubation, $4 \mathrm{~mL}$ of media was added into the flask to assist with cell dislodgement and stop the enzymatic activity of the trypsin. The cells were collected in a $15 \mathrm{~mL}$ falcon tube and centrifuged at $125 \mathrm{G}$ for seven minutes. After centrifugation, the supernatant was removed, and $1 \mathrm{~mL}$ of media was added to homogenize the cells.

Using a $50 \%(\mathrm{v} / \mathrm{v})$ trypan blue (Gibco, Waltham, MA) concentration, the cells were counted using a hemacytometer, and the cells were brought to a concentration of one million cells per $1 \mathrm{~mL}$ of media. They were then seeded by pipetting a $100 \mu \mathrm{L}$ drop of the cell and media mixture on the center of the glass coverslip. This droplet of cells was left for one hour in a $37^{\circ} \mathrm{C}$ incubator with a $5 \% \mathrm{CO}_{2}$ concentration to allow for the cells to attach on the coverslip. Afterwards, an additional $1000 \mu \mathrm{L}$ of media was added to the culture. A media change was done after 24 hours and then changed every three days.

These cells were allowed to grow for one week before of the $20 \mathrm{~mm}$ catheter samples were added into the chamber. Using tweezers, the sterilized catheter segments were placed into two indentations on either side of the well. A mark was made on the side of the catheter without holes to position the sample. The three rows of holes punched into the catheter were oriented with the middle set of holes in direct contact with the cell layer. Labeling of the row of holes was done based on their orientation within the chamber.

At the same time as catheter insertion, the blood was added into the media. A concentration of $15 \mu \mathrm{L}$ of blood per $1 \mathrm{~mL}$ of media was used. This concentration of blood followed the rationale tested in experiments

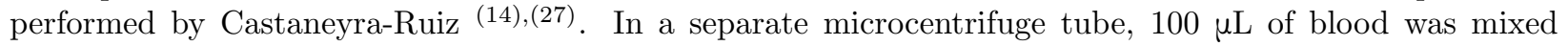
with $\mathrm{CaCl}_{2}$ (Sigma, St. Louis, MO) to obtain a final concentration of $20 \mathrm{mM}$ concentration to reverse the anticoagulation. This solution was then homogenized and added into $5 \mathrm{~mL}$ of media. In the blood exposed samples, $1000 \mu \mathrm{L}$ of the blood and media mixture was pipetted in the each well. The control group used the same chamber system, and the catheter was inserted in the same fashion as described above for the sample with blood. The media used for the control samples was the same as the blood exposed samples without the addition of blood. Media was changed every three days by exchanging spent media with $1000 \mu \mathrm{L}$ fresh media. 


\section{Staining}

Samples ran for a total of two weeks before fixing them with two washes of $0.01 \mathrm{M}$ phosphate buffer solution (PBS) (Sigma, St. Louis, MO). The volume used for the following solutions was $500 \mu \mathrm{L}$ per sample, except for PBS washes which were at $1000 \mu \mathrm{L}$. The cells were then exposed to a $4 \%$ paraformaldehyde (Sigma, St. Louis, MO) solution for seven minutes, followed by two rinses with a $0.01 \mathrm{M}$ PBS. Permeabilization of the cells was done by incubating them in sodium borohydride (Sigma, St. Louis, MO) and a citrate buffer (Sigma, St. Louis, MO) for 30 minutes each. The citrate buffer was heated to $100^{\circ} \mathrm{C}$ before adding it on the samples, and then heated at $80^{\circ} \mathrm{C}$ during the incubation period. Samples were then incubated in BlockAid blocking solution (ThermoFisher, Waltham, MA) for 30 minutes.

Staining the astrocytes was done by using the primary antibody GFAP Polyclonal Antibody (ThermoFisher PA1-10004) and the secondary antibody Goat anti-Chicken IgY 555 ThermoFisher A-21437) for 24 hours each. The antibodies were diluted, using $0.4 \%$ Triton solution in 0.01 M PBS, to 1:1000 for the primaries and 5:1000 for the secondaries. After incubating the samples with the secondary antibodies, the samples were washed with 0.01 M PBS. The nuclei were stained using the DAPI Solution (ThermoFisher, Product No.62248) with a 1:1000 ratio in 0.01 M PBS for 30 minutes.

Imaging and Analysis

Before imaging, the top portion of the chamber was broken off to allow imaging. Using a Caliber I.D. RS-G4 Ribbon Scanning Confocal microscope with lasers set to 405 and 561 wavelength, images of the catheter were taken from above still in the chamber. Images were taken, once the catheter was removed, for the row of holes in direct contact with the cells. Analysis of these 3D images was done using Imaris software to obtain cell counts of each of the three sets of eight holes. Images taken from above the catheter while still in the chamber were taken to count the cells around the sides of the catheter. The image of the row of holes that came into direct contact with the cells were counted using the image taken below the catheter after removal. Counts for DAPI and GFAP were taken individually with a consistent volume. A box was positioned to obtain a cell count around the holes. The holes along the side of the sample used the box dimensions 1800x17000x 125 and 2000x17000x75 around the holes in direct contact with the cells.

\section{Statistical Analysis}

Data collected from the cell counts were analyzed to test for normalcy by using the Anderson Darling equation. Parametric results from the normal distribution test were analyzed by using the Welch test with $[?]=0.05$. Utilization of the Mann-Whitney $\mathrm{U}$ test was done with $[?]=0.05$ for non-parametric results.

Experimental Timeline

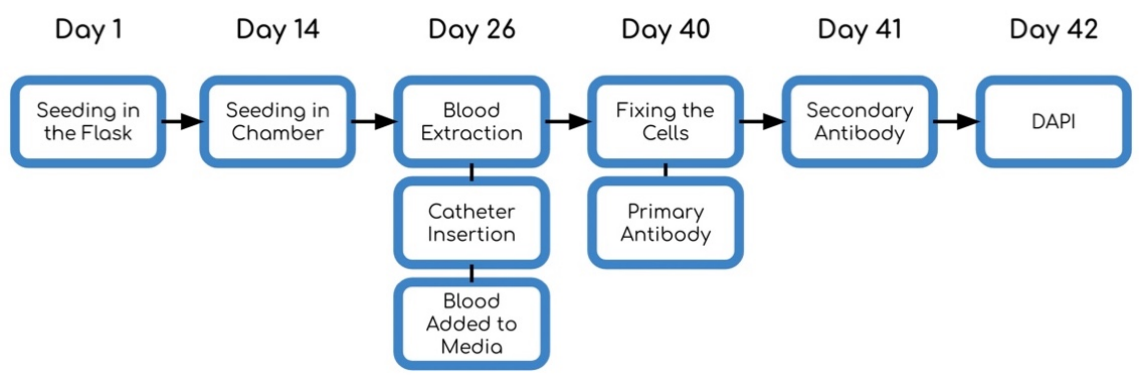

Figure 2: Diagram of the experimental timeline.

\section{Results}

Cell Counts 
Images of the ventricular shunt catheter samples were taken when the catheter was still in the chamber system. The catheters were imaged to include the two rows of holes on the sides of the catheter. Data showed that the cell counts of the blood exposed sample greater than the control group (Figure 3A). Average count of the DAPI and GFAP stains for the control samples were $92.7 \pm 48.7$ and $177.8 \pm 138.1$ cells respectively. The blood exposed sample showed to have an average DAPI count of $475.3 \pm 342.5$ and $1029.5 \pm 429.9$ cell count for GFAP (Table 1). Analysis of the control and blood exposed samples showed a significant increase in cell attachment when exposed to blood $(\mathrm{P}<0.0001)$.

Development of this model was also created to hold enough volume for cell culturing and break the top portion of the chamber for imaging. The ventricular shunt catheter's row of holes in direct contact with the cells (denoted "bottom" because of their orientation in the chamber) were removed from the chambers and imaged for cell counts (Figure 3B). Average cell count of the DAPI stain was $98.8 \pm 39.6$ for the control sample and the blood exposed sample was $225.4 \pm 189.7$ cells. For the GFAP stain the average count was $167.2 \pm 66.9$ and $504.2 \pm 255.5$ for the control and blood exposed sample respectively (Table 1). Comparisons of samples exposed and not exposed to blood showed a significant difference in total cell attachment on the surface of the catheter $(\mathrm{P}<0.001)$.

\section{Discussion}

This study serves as a preliminary investigation into the astrocytic response following BBB rupture from shunt insertion and shows a significant increase in cellular attachment when exposed to blood $(P<0.0001)$. Rupture of the BBB causes and increase in VZ permeability similar to other chronic indwelling devices within the brain ${ }^{(28)}$. Using this $3 \mathrm{D}$ printed in vitromodel, we were able to mimic breaking the BBB and subsequent astrogliosis. In a study done by Castaneyra-Ruiz, it was described that the optimal concentration of blood was $3 \%$ over a 48 -hour time period with higher concentrations, $4 \%$ blood, showing significant cell death. This decrease in cells prevented any observations, at higher concentrations, past the 3-hour time point. Since our experiment ran for two weeks, a significantly longer time period, we opted to decrease our blood concentration to $1.5 \%$ in the media to prevent excessive cell death and allow for a sufficient number of cells to survive for analysis. Certainly, concentration and time-point dependencies will exist, which will be studied in future work. Additionally, the incorporation of a bioreactor-based flow system at physiologic flow and shear rates may augment the possibility for dynamic changes in blood protein adsorption.

Replication of industrial catheters using a leather punch created a rough surface similar to that of industrial made catheters. In previous work, it was shown that these imperfections cause an increase in cellular adhesion (29). The addition of this rough surface may perhaps give rise to an increased opportunity for increased blood protein adsorption and/or astrocyte attachment. Silicone catheters have been known to have relatively hydrophobic properties allowing for an increase in cellular adsorption to the surface ${ }^{(30)}$. Along with the addition of holes creating a rough surface, the hydrophobic characteristic creates a device prone to more cellular attachment.

Choosing to limit the investigation to astrocytes alone was due to the known reactivity after exposure to blood along with its prevalent role in general shunt obstruction ${ }^{(24),(31),(32)}$. Certainly, the acute- and chronicresponse to the shunt catheter is dynamic, multi-factorial, and dependent on environmental conditions. Included in this response, we must consider that the ependymal layer that makes up the ventricular wall breaks down when exposed to blood allowing the astrocytes to migrate into the ventricular space. Catheter contact with the ventricular wall also increases astrocyte density close to the interface between the wall and the shunt catheter ${ }^{(33)}$. Astrogliosis will occur when the cells are exposed to blood following shunt insertion and subsequent breaking of the BBB ${ }^{(20)}$. In future work, we plan run a similar experiment utilizing ependymal cells due to their importance in allowing the activation of astrocytes due to VZ breakdown ${ }^{(14)}$.

Astrocytic response is likely to be due to the bodies intuitive need to repair itself following a trauma ${ }^{(19)}$. Data presented here indicates that the activation of astrocytes, due to blood, increases proliferation of astrocytes following their exposure due to VZ disruption causing the migration to the shunt surface ${ }^{(19)}$. Cell exposure to blood products to represent breaking of the BBB was done and showed an increase of cellular attachment 
to the surface of the catheter around the holes ${ }^{(34)-(36)}$. When comparing the average total cell count for each sample type the DAPI stain, for cell nuclei, is $94.7 \pm 44.5$ for the control and $392.0 \pm 317$ for the blood exposed samples (Figure 4). After running the Mann-Whitney test the p-value was $<0.0001$, which indicates a significant difference between the two cell counts. From this we can determine that the blood had a negative effect on the cells causing an increase in catheter obstruction.

Investigation into the astrocytic response was analyzed by staining with GFAP stains to visualize the astrocytes on the catheter. Comparisons between the control and blood exposed samples show a significant difference in GFAP expression $(P<0.0001)$. These data suggest that there is a potential effect from blood proteins, when added into the media, enhances cell spread and/or cell reactivity. Astrocyte activation occurs in response to stimuli in an effort to repair the brain via proliferation and extension of astrocyte processes $[37,38]$. Perhaps increased concentration and type of protein adsorbed to the polydimethylsiloxane shunt surface enhances the receptor-integrin interplay and increases cell attachment, not just in cell number, but in cell affinity to the surface (Figure 5). Increased GFAP expression after whole blood exposure may also be indicative of enhanced neuroinflammation, cytoskeletal changes, and/or increased cell communication. Since GFAP stains within the cytoplasm, it allows for a single astrocyte to be stained multiple times. The software takes into account intensity and signal diameter when analyzing the cell count, but still can be added to the total count. This could be a methodological explanation for the higher expression in comparison to DAPI. When comparing the cell counts of the control and blood exposed samples of the DAPI and GFAP stains, they were analyzed separately to account for the antibody's expression behaviors.

Cellular attachment to the surface of the shunt showed an insignificant difference of DAPI and GFAP expression along the side of the catheter compared to holes in direct contact to cells for the control samples $(P>0.05)$. The difference in DAPI signal of the blood exposed sample was also insignificant as well, but GFAP expression showed a significantly higher count around the row of holes along the side of the catheter $(P<0.05)$. One possible reason for an insignificant difference is due to the removal of the catheter from the culture. There could have been a potential ripping of cells from the surface of the catheter upon extraction of the shunt. A significant difference in GFAP expression of the blood exposed sample may further indicate that a morphological change occurs following activation of astrocytes.

Blood within the chamber contained no cells that would be positively stained with GFAP, indicating that the expression is limited only to astrocytes. The use of DAPI to stain the DNA within the nucleus is not affected by the addition of blood due to the small amount of blood used along with the majority of the components of blood not containing a nucleus. Small amounts of cells within the blood that could have been pick up by the DAPI stain were filtered out by setting a specific diameter, such that the software only counts the astrocytic nuclei.

\section{Conclusion}

BBB breakdown poses increased propensity for blood to enter the ventricles which significantly increases astrocyte attachment. Since we know astrocytes play a major role in shunt obstruction and failure of shunts used to treat hydrocephalus, this initial study shows the necessity of future work examining the role blood products play in the shunted pathology of hydrocephalus and pushes us to examine ways in which we can inhibit BBB permeability. Future work will examine the rates of shunt insertion and correlated BBB breakdown. Further exploration into this topic will also include an analysis of the role of ependymal cells when exposed to blood following breaking of the BBB.

\section{List of Abbreviations}

CSF - Cerebrospinal Fluid

PHH - Posthemorrhagic Hydrocephalus

IVH - Intraventricular Hemorrhage

ICH - Intracerebral Hemorrhage 
GMH - Germinal Matrix Hemorrhage

BBB - Blood Brain Barrier

NSC - Neural Stem Cells

VZ - Ventricular Zone

PBS - Phosphate Buffer Solution

VOC - Volatile Organic Compounds

AS-3 - Additive Solution Three

DMEM - Dulbecco's Modified Eagle Medium

Conflicts of Interest: The authors declare that they have no conflicts of interest.

Funding: Research reported in this publication was supported by the National Institute of Neurological Disorders and Stroke of the National Institutes of Health under award number R01NS094570. Approximately $90 \%$ was financed with federal dollars. The content is solely the responsibility of the authors and does not necessarily represent the official view of the Hydrocephalus Association or the National Institutes of Health.

\section{Authors' Contributions:}

MZ: Conceptualization, Methodology, Formal Analysis, Investigation, Data Curation, Data Analysis, Project Administration, Writing-Original Draft, Visualization, and Writing-Review and Editing.

RA: Conceptualization, Investigation, Writing-Review and Editing

KZ: Formal Analysis, Data Analysis, Writing-Review and Editing

CH: Conceptualization, Methodology, Resources, Supervision, Project Administration, Funding Acquisition, and Writing-Review and Editing

\section{Acknowledgements}

We would like to acknowledge Wayne State University for allowing us to use their facilities, for this procedure. Dr. James McAllister and Mr. Leandro Castaneyra-Ruiz for assisting with development of methodology for cell culturing. Dr. David Limbrick for help with development of investigation and conceptualization.

\section{Availability Statement}

Raw data were generated at Wayne State University and can be made available to other qualified research scientists for appropriate applications and collaborative efforts in accordance with Wayne State University's materials transfer guidelines as well as those set by NIH and the Hydrocephalus Association. Patentable work will be reviewed by the Wayne State Technology Transfer Office prior to data sharing, were applicable.

\section{References}

1. Pople IK. Hydrocephalus and shunts: What the neurologist should know. Neurol Pract. 2002;73.

2. Corns R, Martin A. Hydrocephalus. Surgery. 2012;30:142-8.

3. Del Bigio MR. Neuropathology and structural changes in hydrocephalus. Dev Disabil Res Rev. 2010;16:1622 .

4. Rekate HL. The definition and classification of hydrocephalus: A personal recommendation to stimulate debate. Cerebrospinal Fluid Res. 2008;5:1-7.

5. Leinonen V, Vanninen R, Rauramaa T. Cerebrospinal fluid circulation and hydrocephalus [Internet]. 1st ed. Handb Clin Neurol. Elsevier B.V.; 2018. 39-50 p. Available from: http://dx.doi.org/10.1016/B978-0-12802395-2.00005-5 
6. Harris C, Pearson K, Hadley K, Zhu S, Browd S, Hanak BW, Shain W. Fabrication of three-dimensional hydrogel scaffolds for modeling shunt failure by tissue obstruction in hydrocephalus. Fluids Barriers CNS. $2015 ; 12: 1-15$.

7. Sarkiss CA, Sarkar R, Yong W, Lazareff JA. Time dependent pattern of cellular characteristics causing ventriculoperitoneal shunt failure in children. Clin Neurol Neurosurg [Internet]. Elsevier B.V.; 2014;127:30-2. Available from: http://dx.doi.org/10.1016/j.clineuro.2014.09.029

8. Drake JM, Kestle JRW, Tuli S. CSF shunts 50 years on - Past, present and future. Child's Nerv Syst. 2000;16:800-4.

9. Bonfield TL, Colton E, Anderson JM. Protein adsorption of biomedical polymers influences activated monocytes to produce fibroblast stimulating factors. J Biomed Mater Res. 1992;26:457-65.

10. Del Bigio MR. Biological reactions to cerebrospinal fluid shunt devices: a review of the cellular pathology. Neurosurgery. United States; 1998;42:316-9.

11. Strahle J, Garton HJL, Maher CO, Muraszko KM, Keep RF, Xi G. Mechanisms of Hydrocephalus After Neonatal and Adult Intraventricular Hemorrhage. Transl Stroke Res. 2012;3:25-38.

12. Bhattathiri PS, Gregson B, Prasad KSM, Mendelow AD. Intraventricular hemorrhage and hydrocephalus after spontaneous intracerebral hemorrhage: Results from the STICH trial. Acta Neurochir Suppl. 2006;65-8.

13. McAllister JP, Guerra MM, Ruiz LC, Jimenez AJ, Dominguez-Pinos D, Sival D, den Dunnen W, Morales DM, Schmidt RE, Rodriguez EM, Limbrick DD. Ventricular zone disruption in human neonates with intraventricular hemorrhage. J Neuropathol Exp Neurol. 2017;76:358-75.

14. Castaneyra-Ruiz L, Morales DM, McAllister JP, Brody SL, Isaacs AM, Strahle JM, Dahiya SM, Limbrick DD. Blood exposure causes ventricular zone disruption and glial activation in vitro. J Neuropathol Exp Neurol. 2018;77:803-13.

15. Jaeger CB, Winn SR, Tresco PA, Aebischer P. Repair of the blood-brain barrier following implantation of polymer capsules. Brain Res. 1991;551:163-70.

16. Yang C, Hawkins KE, Doré S, Candelario-Jalil E. Neuroinflammatory mechanisms of blood-brain barrier damage in ischemic stroke. Am J Physiol - Cell Physiol. 2019;316:C135-53.

17. Del Bigio MR. Biological reactions to cerebrospinal fluid shunt devices: A review of the cellular pathology. Neurosurgery. 1998;42:319-26.

18. Achyuta AKH, Stephens KD, Lewis HGP, Murthy SK. Mitigation of reactive human cell adhesion on poly(dimethylsiloxane) by immobilized trypsin. Langmuir. 2010;26:4160-7.

19. Harris C, Pearson K, Hadley K, Zhu S, Browd S, Hanak BW, Shain W. Fabrication of three-dimensional hydrogel scaffolds for modeling shunt failure by tissue obstruction in hydrocephalus. Fluids Barriers CNS. BioMed Central; 2015;12:1-15.

20. Ding Y, Zhang T, Wu G, McBride DW, Xu N, Klebe DW, Zhang Y, Li Q, Tang J, Zhang JH. Astrogliosis inhibition attenuates hydrocephalus by increasing cerebrospinal fluid reabsorption through the glymphatic system after germinal matrix hemorrhage. Exp Neurol [Internet]. Elsevier; 2019;320:113003. Available from: https://doi.org/10.1016/j.expneurol.2019.113003

21. Klebe D, McBride D, Krafft PR, Flores JJ, Tang J, Zhang JH. Posthemorrhagic hydrocephalus development after germinal matrix hemorrhage: Established mechanisms and proposed pathways. J Neurosci Res. 2020;98:105-20.

22. Brydon HL, Keir G, Thompson EJ, Bayston R, Hayward R, Harkness W. Protein adsorption to hydrocephalus shunt catheters: CSF protein adsorption. J Neurol Neurosurg Psychiatry. 1998;64:643-7. 
23. Roales-Buján R, Páez P, Guerra M, Rodríguez S, Vío K, Ho-Plagaro A, García-Bonilla M, RodríguezPérez LM, Domínguez-Pinos MD, Rodríguez EM, Pérez-Fígares JM, Jiménez AJ. Astrocytes acquire morphological and functional characteristics of ependymal cells following disruption of ependyma in hydrocephalus. Acta Neuropathol. 2012;124:531-46.

24. Cozzens JW, Chandler JP. Increased risk of distal ventriculoperitoneal shunt obstruction associated with slit valves or distal slits in the peritoneal catheter. J Neurosurg. 1997;87:682-6.

25. Jiménez AJ, Domínguez-Pinos MD, Guerra MM, Fernández-Llebrez P, Pérez-Fígares JM. Structure and function of the ependymal barrier and diseases associated with ependyma disruption. Tissue Barriers. $2014 ; 2: 1-14$.

26. Heaton A, Keegan T, Holme S. In vivo regeneration of red cell 2,3-diphosphoglycerate following transfusion of DPG-depleted AS-1, AS-3 and CPDA-1 red cells. Br J Haematol. 1989;71:131-6.

27. Castaneyra-Ruiz L, McAllister JP, Morales DM, Brody SL, Isaacs AM, Limbrick DD. Preterm intraventricular hemorrhage in vitro: Modeling the cytopathology of the ventricular zone. Fluids Barriers CNS [Internet]. BioMed Central; 2020;17:1-11. Available from: https://doi.org/10.1186/s12987-020-00210-7

28. Skousen JL, Bridge MJ, Tresco PA. A strategy to passively reduce neuroinflammation surrounding devices implanted chronically in brain tissue by manipulating device surface permeability. Biomaterials [Internet]. Elsevier Ltd; 2015;36:33-43. Available from: http://dx.doi.org/10.1016/j.biomaterials.2014.08.039

29. Harris CA, McAllister JP. Does drainage hole size influence adhesion on ventricular catheters? Child's Nerv Syst. 2011;27:1221-32.

30. Anderson JM, Rodriguez A, Chang DT. Foreign body reaction to biomaterials. Semin Immunol [Internet]. 2007/12/26. 2008;20:86-100. Available from: https://pubmed.ncbi.nlm.nih.gov/18162407

31. Chittiboina P, Pasieka H, Sonig A, Bollam P, Notarianni C, Willis BK, Nanda A. Posthemorrhagic hydrocephalus and shunts: What are the predictors of multiple revision surgeries? Clinical article. J Neurosurg Pediatr. 2013;11:37-42.

32. Bir SC, Konar S, Maiti TK, Kalakoti P, Bollam P, Nanda A. Outcome of ventriculoperitoneal shunt and predictors of shunt revision in infants with posthemorrhagic hydrocephalus. Child's Nerv Syst [Internet]. Child's Nervous System; 2016;32:1405-14. Available from: http://dx.doi.org/10.1007/s00381-016-3090-6

33. Del Bigio MR, Fedoroff S. Short-term response of brain tissue to cerebrospinal fluid shunts in vivo and in vitro. J Biomed Mater Res. 1992;26:979-87.

34. Collins P, Hockley AD, Woollam DHM. Surface ultrastructure of tissues occluding ventricular catheters. J Neurosurg. 1978;48:609-13.

35. Beer R, Pfausler B, Schmutzhard E. Management of nosocomial external ventricular drain-related ventriculomeningitis. Neurocrit Care. 2009;10:363-7.

36. Lewis A, Taylor Kimberly W. Prediction of ventriculoperitoneal shunt placement based on type of failure during external ventricular drain wean. Clin Neurol Neurosurg [Internet]. Elsevier B.V.; 2014;125:109-13. Available from: http://dx.doi.org/10.1016/j.clineuro.2014.07.022

37. Schiweck J, Eickholt BJ, Murk K. Important shapeshifter: Mechanisms allowing astrocytes to respond to the changing nervous system during development, injury and disease. Front Cell Neurosci. 2018;12:1-17.

38. Sterpka A, Yang J, Strobel M, Zhou Y, Pauplis C, Chen X. Diverged morphology changes of astrocytic and neuronal primary cilia under reactive insults. Mol Brain. Molecular Brain; 2020;13:1-16. 

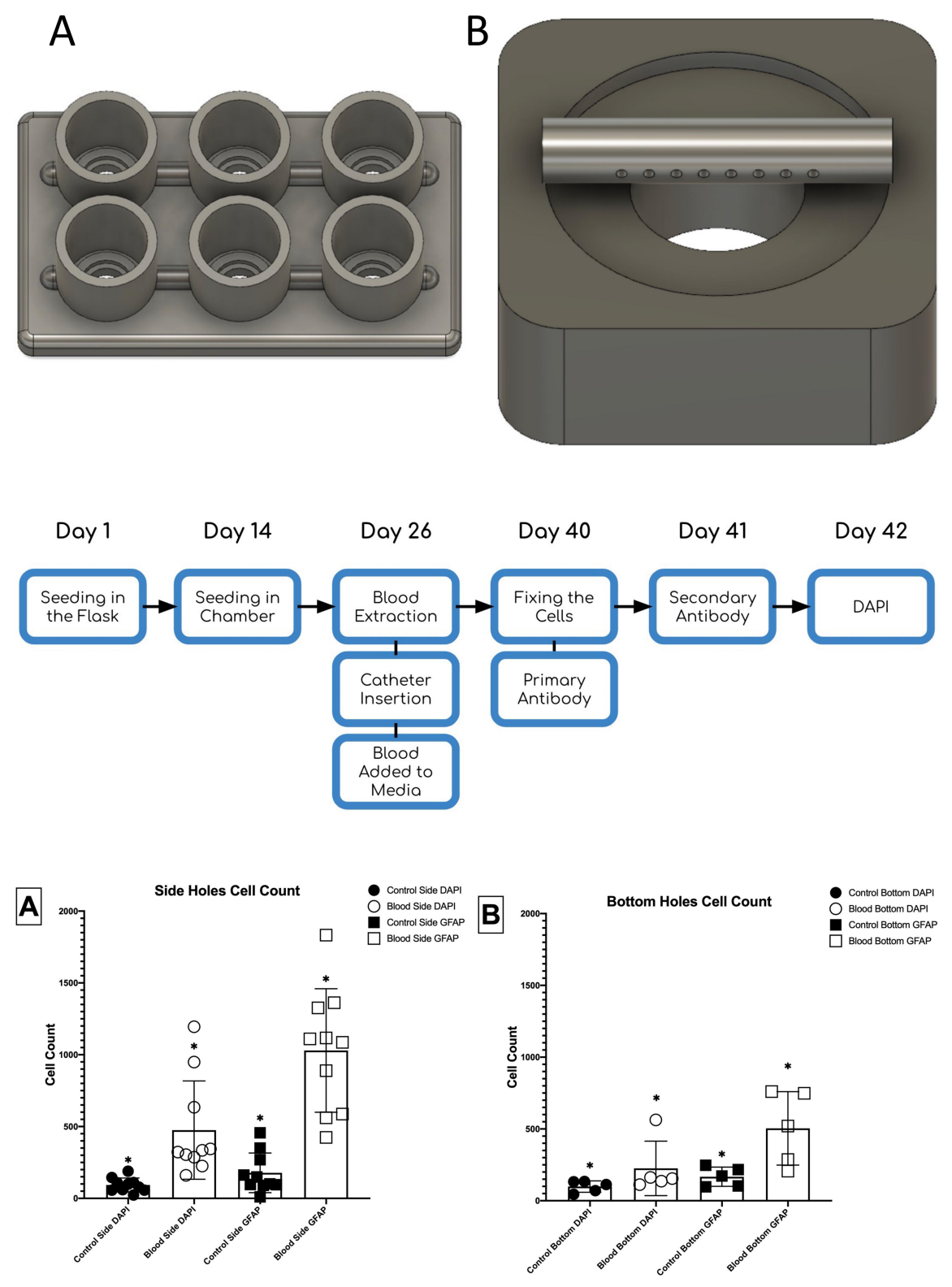

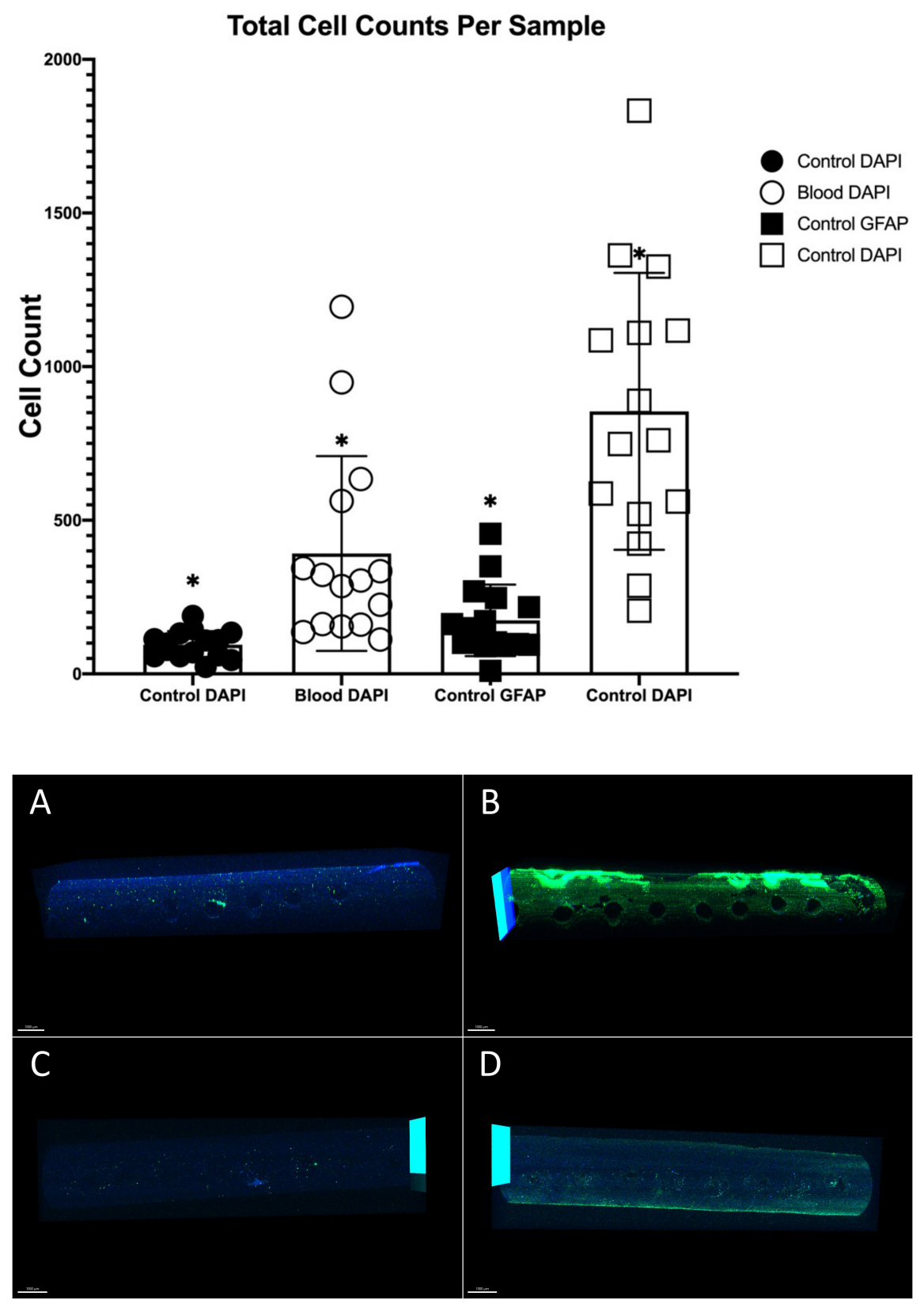


\begin{tabular}{|c|c|c|}
\hline & DAPI & GFAP \\
\hline Control Side & $92.7 \pm 48.7$ & $177.8 \pm 138.1$ \\
\hline Blood Side & $475.3 \pm 342.5$ & $1029.5 \pm 429.9$ \\
\hline Control Bottom & $98.8 \pm 39.6$ & $167.2 \pm 66.9$ \\
\hline Blood Bottom & $225.4 \pm 189.7$ & $504.2 \pm 255.5$ \\
\hline Total Control & $94.7 \pm 44.5$ & $174.3 \pm 116.5$ \\
\hline Total Blood & $392.0 \pm 317.1$ & $854.4 \pm 450.7$ \\
\hline
\end{tabular}

